\title{
Predictive factors for the success of McRoberts' manoeuvre and suprapubic pressure in relieving shoulder dystocia: a cross-sectional study
}

\author{
Zara Lin Zau Lok, Yvonne Kwun Yue Cheng and Tak Yeung Leung ${ }^{*}$
}

\begin{abstract}
Background: McRoberts' and suprapubic pressure are often recommended as the initial choices of manoeuvres to manage shoulder dystocia, as they are believed to be less invasive compared to other manoeuvres. However, their success rates range from 23 to $40 \%$. This study aims to investigate the predictive factors for the success of McRoberts' manoeuvre with or without suprapubic pressure $(M+/-S)$.

Methods: All cases of shoulder dystocia in a tertiary hospital in South East Asia were recruited from 1995 to 2009. Subjects were analysed according to either 'success' or 'failure' of $\mathrm{M}+/-\mathrm{S}$. Maternal and fetal antenatal and intrapartum factors were compared by univariate and multivariate analysis.

Results: Among 198 cases of shoulder dystocia, $\mathrm{M}+/-\mathrm{S}$ as the primary manoeuvre was successful in $25.8 \%$. The other $74.2 \%$ needed either rotational or posterior arm manoeuvres or combination of manoeuvres. Instrumental delivery was the single most significant factor associated with an increased risk of failed $\mathrm{M}+/-\mathrm{S}$ on logistic regression ( $p<0.001, \mathrm{OR} 4.88,95 \% \mathrm{Cl} 2.05-11.60$ ). The success rate of $\mathrm{M}+/-\mathrm{S}$ was only $15.0 \%$ if shoulder dystocia occurred after instrumental delivery but was $47.7 \%$ after spontaneous vaginal delivery.

Conclusions: When shoulder dystocia occurs after instrumental vaginal delivery, the chance of failure of $M+/-S$ is $85 \%$, which is 4.7 times higher than that after spontaneous vaginal delivery. Hence all operators performing instrumental delivery should be proficient in performing all manoeuvres to relieve shoulder dystocia when $\mathrm{M}+/-\mathrm{S}$ cannot do so.
\end{abstract}

Keywords: McRoberts' manoeuvre, Suprapubic pressure, Shoulder dystocia, Instrumental delivery, Vacuum extraction

\section{Background}

Shoulder dystocia is an uncommon obstetric emergency with a quoted incidence ranging from 0.58 to $0.7 \%$ [1]. In a brief few minutes it can lead to fetal morbidity and mortality [2-4], and in attempt to expedite delivery also maternal morbidity such as postpartum haemorrhage and major perineal tears [5]. An attempt to identify predictors of shoulder dystocia to sanction the option of caesarean section has only returned risk factors with low

\footnotetext{
*Correspondence: tyleung@cuhk.edu.hk Department of Obstetrics and Gynaecology, The Chinese University of Hong Kong, Prince of Wales Hospital, 30-32 Ngan Shing Street, Shatin, Hong Kong SAR, China
}

predictive value [6, 7]. Due to the unpredictable and difficult nature of shoulder dystocia many professional bodies advocate regular simulated training with high fidelity ( gorithms are to perform McRoberts' manoeuvre and suprapubic pressure in the first instance, and a failure of these two methods should be followed by other manoeuvres such as rotational methods, posterior arm delivery and all- fours manoeuvre. More injurious manoeuvres such as clavicular fracture, symphysiotomy and Zavanelli 
Table 1 The details of HELPERR and BE CALM Mnemonics

\begin{tabular}{ll}
\hline HELPERR Mnemonics & BE CALM Mnemonics \\
\hline Help: call for help & Breathe, do not push \\
Evaluate for episiotomy & $\begin{array}{l}\text { Elevate the legs into McRoberts } \\
\text { position }\end{array}$ \\
$\begin{array}{l}\text { Legs: McRoberts position } \\
\text { Pressure: Suprapubic pressure }\end{array}$ & $\begin{array}{l}\text { Apply suprapubic pressure } \\
\text { Enter manoeuvres: perform internal }\end{array}$ \\
$\begin{array}{l}\text { EnLarge the vaginal opening: } \\
\text { perform episiotomy if more room } \\
\text { is needed for manoeuvres }\end{array}$ \\
Remove the posterior arm & $\begin{array}{l}\text { Manoeuvres deliver the posterior } \\
\text { arm or perform rotational } \\
\text { manoeurres }\end{array}$ \\
& \\
\hline Roll the patient onto all fours &
\end{tabular}

manoeuvres are rarely used due to the high success rates of the less invasive manoeuvres $[5,13,14]$.

McRoberts' and suprapubic pressure are often recommended as the initial choices of manoeuvres because they are believed to be less invasive compared to other manoeuvres, which require the insertion of operators' hands into the vagina. However, even well conducted McRoberts' manoeuvre and suprapubic pressure do not guarantee success of delivery without injury. Studies from previous cohorts have claimed success rates ranging from 23.2 to 58 \% for McRoberts' manoeuvre alone or in combination with suprapubic pressure $[5,13,15]$. In order to perform McRoberts' manoeuvre and suprapubic pressure correctly and effectively, there must be adequate staff available, including two persons to hyperflex the maternal hips (one on each side), a third one to apply suprapubic pressure, and another one to apply traction on the fetal head. Failure to summon additional staff to assist immediately may delay the use of more effective rotational methods or posterior arm delivery, and increase the risk of fetal hypoxia [2]. Thus it is necessary to review the usefulness of these frequently used firstline manoeuvres, by investigating which factors contributing to their success or failure, and in doing so decide how strongly one must adhere to a fixed protocol in each scenario.

The root of this current review stems from two previous studies published by our group regarding the headto-shoulder delivery interval and perinatal outcomes of shoulder dystocia [2, 3]. We subsequently noted that the $25 \%$ success rate of McRoberts' manoeuvre and suprapubic pressure in our Asian centre was similar to a recently published paper from the Netherlands (23.8\%) [16], but was significantly lower than that reported in other predominantly Caucasian centres such as that of MacKenzie et al. and Gherman et al. (46 and $42 \%$ respectively) $[13,15]$. There are only a few reports on the success rate of McRoberts' manoeuvre and suprapubic pressure in relieving shoulder dystocia. This led us to investigate the predictive factors for the success of McRoberts' manoeuvre with or without suprapubic pressure $(\mathrm{M}+/-\mathrm{S})$.

\section{Methods}

This cross-sectional study was conducted in a tertiary university hospital in Hong Kong with an annual delivery of more than 6000. All consecutive cases of shoulder dystocia reported from 1995 to 2009 inclusively were identified from our hospital electronic database. As per our previous studies [2, 3], shoulder dystocia was defined as either a need to perform an additional obstetric manoeuvre in addition to downward traction of the fetal neck or when the head to body delivery interval was longer than $1 \mathrm{~min}$ [17]. Cases were only included for analysis if McRoberts' manoeuvre with or without suprapubic pressure $(\mathrm{M}+/-\mathrm{S})$ was the first manoeuvre performed, and documentation was available regarding the management of dystocia. Cases of intrauterine fetal death or fetal malformations were excluded. Our unit protocol for the management of shoulder dystocia was based on and similar to the Green Top Guideline on shoulder dystocia published by the Royal the College of Obstetricians \& Gynaecologists [1]. All midwives and obstetricians took part in annual drills on the management of shoulder dystocia. In all cases, unless otherwise stated, McRoberts' combined with suprapubic pressure was the first manoeuvre attempted. If this failed other manoeuvres would be attempted based on the operators' experience at the time. A nurse was always designated to document time sequences, in particular head and body delivery times. At least one obstetrician and one paediatrician would attend the cases at the time of diagnosis. All instrumental deliveries in our unit were conducted by obstetricians. All cases of shoulder dystocia were audited in a monthly meeting and logged. Unless otherwise stated, $\mathrm{M}+\mathrm{l}-\mathrm{S}$ in this study refers to the use of McRoberts' manoeuvre with or without suprapubic pressure, as our unit protocol requires the two to be carried out simultaneously.

Identified cases were traced and medical records were searched for factors of interest, which included both maternal and neonatal antenatal and intrapartum characteristics. Maternal age was noted and advanced maternal age was defined as 35 years or above. Maternal height was defined as short stature if $150 \mathrm{~cm}$ or less. Maternal body weight at booking and at the time of delivery was recorded to calculate the body mass index (BMI) at the two corresponding time points, and women were classified as obese according to the World Health Organization cut-off of $30 \mathrm{~kg} / \mathrm{m}^{2}$ [18]. Maternal ethnicity, parity, history of shoulder dystocia and presence of diabetes mellitus were also noted. Intrapartum characteristics included the onset of labour, mode of delivery, 
use of epidural analgesia, and duration of the second stage of labour. Prolonged second stage was defined as more than $60 \mathrm{~min}$. Neonatal characteristics of note included gestational age, neonatal sex and birth weight.

Analysis was done using $\mathrm{IBM}^{\circ} \mathrm{SPSS}^{\circ}$ Statistics version 22 (IBM, N.Y., USA). Maternal antenatal and intrapartum characteristics and neonatal demographics were analysed in relation to the success of $\mathrm{M}+/-\mathrm{S}$ using Chisquare test for categorical independent variables and independent $t$-test for continuous independent variables. All variables with $p<0.2$ on univariate analysis were further recruited for multivariate analysis. The level of statistical significance was set at $p<0.05$.

Ethical approval for this study was obtained from the Institutional Review Board 'Joint The Chinese University of Hong Kong - New Territories East Cluster Clinical Research Ethics Committee' (Ref. No. CRE-2010.029) on 04 February 2010.

\section{Results}

A total of 210 cases of shoulder dystocia were identified amongst the 62,295 singleton vaginal deliveries from 1995 to 2009 inclusively. The incidence of $0.34 \%$ is comparable to those reported worldwide [19]. Twelve cases were excluded from analysis, as $\mathrm{M}+/-\mathrm{S}$ was not the first manoeuvre performed. Of the remaining 198 cases, majority of the women in this cohort were Chinese $(94.9 \%$ ), with the remaining $5.1 \%$ being of South Asian ethnicity including Filipino, Indian, Pakistani, Indonesian, Thai and Vietnamese. The mean maternal age was $31.0 \pm 4.9$ years and $77.2 \%$ were aged less than 35 years at the time of delivery. There were 96 nulliparous and 102 multiparous women, and none of them had previous history of shoulder dystocia. One hundred thirty-three (67.2 \%) needed instrumental delivery (130 vacuum extractions and three forceps deliveries), and all were performed by obstetricians. The indication for instrumental delivery was either 'fetal distress' (56 cases, $42.1 \%$ ) or 'prolonged second stage of labour' (77 cases, $57.9 \%)$. Fifty-one cases $(25.8 \%)$ were delivered successfully with $\mathrm{M}+/-\mathrm{S}$; of this 21 (41.2\%) were by midwives alone. For the other 147 cases who had failed $\mathrm{M}+/-\mathrm{S}$, additional obstetric manoeuvres such as rotational or posterior arm delivery or combination of the two were performed to achieve delivery as reported in our previous study [3]. No case needed all-fours manoeuvre, symphysiotomy, Zavanelli manoeuvre or caesarean section, and all babies were delivered live at birth. There were 4 cases of brachial plexus injury $(7.8 \%)(N=4)$ in the success group and $10(6.8 \%)$ in the failed group $(p=0.946)$. Other perinatal outcomes were reported separately in our previous studies $[2,3]$.

Table 2 listed the comparison of maternal factors, intrapartum factors and neonatal factors between the success group and the failed $\mathrm{M}+/-\mathrm{S}$ group. There were no statistical differences between the failed group and the successful group in terms of Chinese ethnicity (95.2\% vs. $94.1 \%)$, maternal age (31 year old vs. 30 year old), maternal height (156 cm vs. $156 \mathrm{~cm})$, BMI at booking $\left(24.1 \mathrm{~kg} / \mathrm{m}^{2}\right.$ vs. $\left.24.8 \mathrm{~kg} / \mathrm{m}^{2}\right)$, proportion of nulliparity (51.7\% vs $39.2 \%)$, and presence of diabetes mellitus ( 8.8 \% vs. $11.8 \%$ ). However, women in the failed group were statistically significantly lighter than those in the success group in terms of their mean maternal body weight at delivery (68.1 $\mathrm{kg}$ vs. $71.7 \mathrm{~kg}, p=0.034)$, and their mean BMI at delivery $\left(27.8 \mathrm{~kg} / \mathrm{m}^{2}\right.$ vs. $29.2 \mathrm{~kg} / \mathrm{m}^{2}$, $p=0.015$ ). The proportion of obese women (BMI at delivery of $30 \mathrm{~kg} / \mathrm{m}^{2}$ or more) was significantly lower in the failed group ( $21.1 \%$ vs. $33.3 \% ; p=0.049)$.

For intrapartum factors of those who failed $\mathrm{M}+/-\mathrm{S}, 34$ $(23.1 \%)$ followed spontaneous delivery of the head, while 113 (76.9 \%) followed instrumental delivery, (111 vacuum extractions and two forceps deliveries). Instrumental delivery was significantly higher in the failed group (76.9\%) when compared to the success group $(39.2 \% ; p<0.001)$. The second stage of labour was more likely to be prolonged in the failed group $(41.5 \%$ vs. $25.5 \% ; p=0.043$ ), but there was no difference in term of induction of labour ( $23.8 \%$ vs. $15.7 \% ; p=0.285)$ or the use of epidural analgesia (17.0 \% vs. $11.8 \% ; p=0.375)$. There was also no difference in terms of gestational age (39 weeks vs. 39 weeks, $p=0.658)$, infant sex $(\mathrm{p}=0.379)$ or body weight at birth (3.78 kg vs. $3.87 \mathrm{~kg}, p=0.178$ ).

After multivariate analysis of variables associated with failure of $\mathrm{M}+/-\mathrm{S}$, only instrumental delivery remained to be the single significant factor for the failure of $\mathrm{M}+/-\mathrm{S}$ in shoulder dystocia $(p<0.001$, OR $4.88,95 \%$ CI $2.05-$ 11.60; Table 3). The success rate of $\mathrm{M}+/-\mathrm{S}$ in the event of shoulder dystocia was only $15.0 \%$ if occurring after instrumental delivery, but was $47.7 \%$ if occurring after natural delivery of the fetal head.

\section{Discussion}

Although many factors such as maternal weight, height, BMI [20], and infant birth weight [7] may affect the success of McRoberts' manoeuvre and suprapubic pressure $(\mathrm{M}+/-\mathrm{S})$, we have identified instrumental delivery to be the single most significant factor which increases the risk of failure of $\mathrm{M}+/-\mathrm{S}$ during shoulder dystocia after multivariate analysis $(p<0.001$, OR 4.88$)$. We did not find statistical relationship between the success of $\mathrm{M}+/-\mathrm{S}$ and parity, maternal body weight, height or BMI, and infant birth weight. Although the presence of prolonged second stage of labour and maternal $B M I \geq 30 \mathrm{~kg} / \mathrm{m}^{2}$ at the time of delivery was shown significant in univariate analysis, they lost significance on multivariate analysis.

The $25.8 \%$ success rate of $\mathrm{M}+/ \mathrm{S}$ in our Asian centre was similar to a midwifery cohort from the Netherlands 
Table 2 Maternal, Fetal Antenatal and Intrapartum Characteristics of Women with Shoulder Dystocia $(N=198)$ McRoberts' manoeuvre with and without suprapubic pressure

\begin{tabular}{llll}
\hline Fail & Success & $p$ \\
& $(n=147)$ & $(n=51)$ &
\end{tabular}

Maternal Characteristics

Ethnicity Chinese $\quad 140(95.2) \quad 48(94.1)$

Maternal Age Other Asian

$7(4.8)$

$3(5.9)$

0.753

Mean \pm SD

$31 \pm 4.8$

$30 \pm 5.2$

0.300

$<35$ years

$113(76.9)$

40 (78.4)

$\geq 35$ years

$34(23.1)$

$11(21.6)$

0.819

Maternal Height $(\mathrm{cm})^{a}$

$>150$

$156 \pm 6.0 \quad 156 \pm 5.5$

0.737

$\leq 150$

120 (81.6) $45(88.2)$

Maternal Weight

at delivery $(\mathrm{kg})$

Maternal BMI at booking $\left(\mathrm{kg} / \mathrm{m}^{2}\right)^{b}$

Mean \pm SD

(7.8)

0.144

$68.1 \pm 9.9 \quad 71.7 \pm 9.2 \quad 0.034$

Maternal BMl at

delivery $\left(\mathrm{kg} / \mathrm{m}^{2}\right)^{c}$

$$
<30
$$

$24.8 \pm 3.5$$$
\geq 30
$$

$128(87.1) \quad 45(88.2)$

$\geq 30$

$14(9.5) \quad 2(3.9)$

0.312

Mean \pm SD

$<30$

$27.8 \pm 3.4$

$29.2 \pm 3.5$

0.232

delivery $\left(\mathrm{kg} / \mathrm{m}^{2} \mathrm{c}\right.$

$$
\geq 30
$$

Parity

Nulliparous

$108(72.5) \quad 29(56.9)$

$31(21.1) \quad 17(33.3)$

$76(51.7) \quad 20(39.2)$

Multiparous

Pre-existing/Gestational No

Diabetes Mellitus

$$
\text { Yes }
$$

$71(48.3) \quad 31(60.8)$

134 (91.1) 45 (88.2)

$13(8.8) \quad 6(11.8)$

Intrapartum Characteristics

$\begin{array}{lllll}\text { Onset of Labour } & \text { Spontaneous } & 112(76.2) & 43(84.3) & \\ & \text { Induced } & 35(23.8) & 8(15.7) & 0.285 \\ \begin{array}{l}\text { Duration of 2 } \\ \text { (minutes) }^{\text {nd }}\end{array} & \text { Mean } \pm \text { SD } & 55 \pm 41.2 & 42 \pm 40.7 & 0.056 \\ & \text { Normal } & 84(57.1) & 37(72.5) & \\ & (\leq 60 \text { min) } & & & \\ & \begin{array}{l}\text { Prolonged } \\ (>60 \text { min) }\end{array} & 61(41.5) & 13(25.5) & 0.043 \\ \text { Mode of Delivery } & \begin{array}{l}\text { Spontaneous } \\ \text { vaginal }\end{array} & 34(23.1) & 31(60.8) & \\ & \text { Instrumental } & 113(76.9) & 20(39.2) & <0.001 \\ \text { Epidural } & \text { With } & 25(17.0) & 6(11.8) & \\ & \text { Without } & 122(83.0) & 45(88.2) & 0.375\end{array}$

Infant Characteristics

\begin{tabular}{lllll} 
Gestation (weeks) & & $39 \pm 1.2$ & $39 \pm 1.2$ & 0.658 \\
Sex & Male & $91(61.9)$ & $28(54.9)$ & \\
& Female & $56(38.1)$ & $23(45.1)$ & 0.379 \\
Body Weight (kg) & Mean \pm SD & $3.78 \pm 0.39$ & $3.87 \pm 0.38$ & 0.178 \\
& $<4 \mathrm{~kg}$ & $102(69.4)$ & $33(64.7)$ & \\
& $\geq 4 \mathrm{~kg}$ & $45(30.6)$ & $18(35.3)$ & 0.536 \\
\hline
\end{tabular}

Note: Data presented as $\mathrm{n}(\%)$ or mean \pm standard deviation; $S D$ standard deviation a: 5 missing data; b:9 missing data; c:13 missing data; $d: 3$ missing data
Table 3 Multivariate logistic regression of factors associated with failure of McRoberts' manoeuvre and suprapubic pressure

\begin{tabular}{lcc}
\hline & $p$ & OR $(95 \% \mathrm{Cl})$ \\
\hline Parity & 0.641 & $0.80(0.32-2.03)$ \\
Short maternal height $(\leq 150 \mathrm{~cm})$ & 0.146 & $0.31(0.07-1.50)$ \\
Maternal weight at delivery $(\mathrm{kg})$ & 0.619 & $1.03(0.93-1.13)$ \\
Maternal BMl at delivery $\left(\mathrm{kg} / \mathrm{m}^{2}\right)$ & 0.279 & $0.85(0.63-1.14)$ \\
Obesity $\left(\mathrm{BMI} \geq 30 \mathrm{~kg} / \mathrm{m}^{2}\right)$ at delivery & 0.663 & $0.75(0.20-2.76)$ \\
Instrumental delivery & $<0.001$ & $4.88(2.05-11.60)$ \\
Duration of second stage & 0.619 & $1.00(0.98-1.11)$ \\
Prolonged second stage $(>60 \mathrm{mins})$ & 0.612 & $0.64(0.12-3.55)$ \\
Birth weight of baby & 0.828 & $1.00(1.00-1.001)$ \\
\hline
\end{tabular}

reported by Kallianidis et al. (23.8 \%) [16], but was significantly lower than that of MacKenzie et al. and Gherman et al. (46 and $42 \%$ respectively) [13, 15]. Notable differences between our cohort and those of Gherman et al. [15] and MacKenzie et al. [13] are that, Gherman et al's consisted mainly of multiparous women $(86 \%)$ with spontaneous vaginal deliveries $(90.4 \%)$ and ethnically Caucasian, as opposed to our cohort of $52 \%$ multiparous and $48 \%$ nulliparous women, who delivered predominantly by instrumental delivery (67.2\%), and were ethnically Asian. As instrumental delivery appears to be a key factor in the failure of $\mathrm{M}+/-\mathrm{S}$, that Gherman et al. had fewer instrumental deliveries may account for the difference in the success rate. Likewise, only $35.4 \%$ had instrumental delivery in MacKenzie et al's study [13]. On the other hand, in the Dutch cohort reported by Kallianidis et al., $92 \%$ were multiparous after spontaneous birth but they yielded only a success rate of $23.8 \%[16]$.

Although instrumental delivery is a known risk factor causing shoulder dystocia [21, 22], its association with failure of $\mathrm{M}+/-\mathrm{S}$ is a new finding and the underlying mechanism is not well known. In spontaneous vaginal delivery, uterine contractions and maternal effort cause gradual and synchronized descent of the fetal head and shoulders. Contrasting instrumental delivery where the head is pulled out by a stronger force in a relatively short period of time resulting in rapid descent of the fetal head and shoulders through the pelvis [20, 23]. It was estimated that during a vacuum extraction, the traction force on the fetus is up to $294 \mathrm{~N}$ [24], nine times higher than the usual force of spontaneous delivery [25]. This may result in the shoulders, especially the posterior shoulder, not descending along the curved sacral path synchronously with the pulled head. After delivery of the head, the posterior shoulder may still be well above the sacral promontory or mid-level of sacrum, hence is unresponsive to McRoberts' manoeuvre, which improves the relative shoulder-to-pelvic dimension by only $1 \mathrm{~cm}$ 


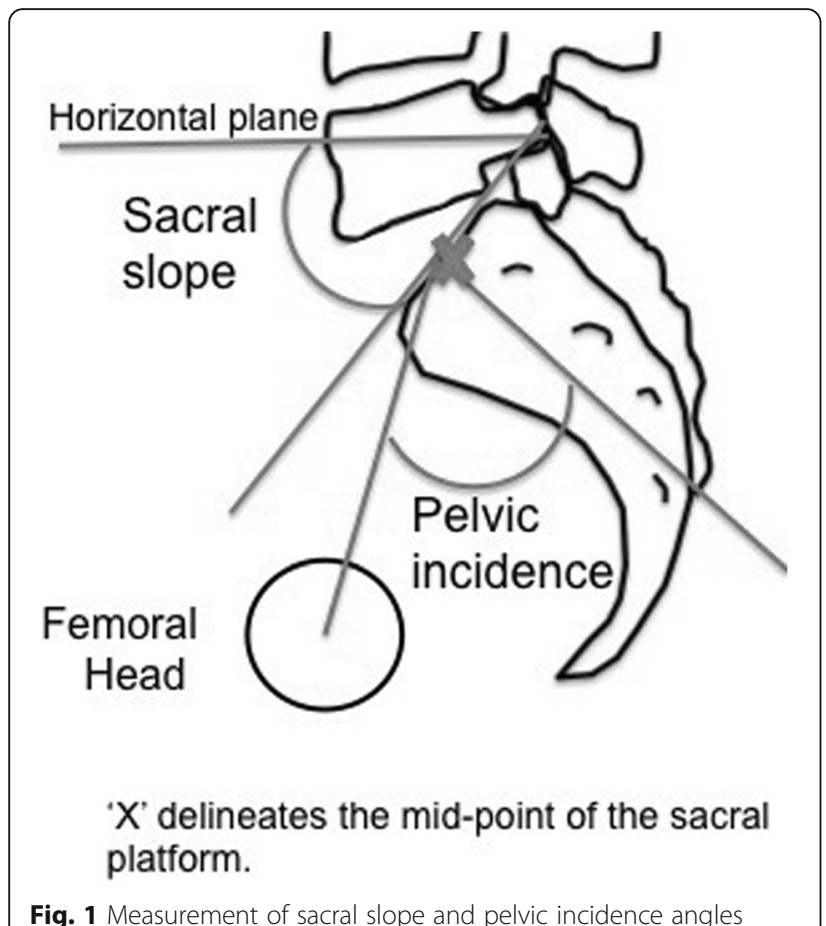

[26]. The mal-descended shoulders may also fail to respond to suprapubic pressure, which only attempts to rotate the anterior, and not the posterior shoulder. Therefore, instrumental delivery increases the risk of shoulder dystocia occurrence in addition to rendering McRoberts' manoeuvre and suprapubic pressure unsuccessful in such circumstances.

Ethnic differences in pelvic anatomy may affect the success rate of $\mathrm{M}+/-\mathrm{S}$, although even among different Caucasian cohorts the reported success rate varies from $23.8 \%$ [16] to $46 \%$ [13]. In an analysis comparing radiological pelvic parameters between Mexicans, Caucasians and Asians it was found that Asians have a lesser sacral slope and pelvic incidence [23]. The sacral slope is the angle created by the horizontal plane and sacral platform when standing, or by the vertical plane when supine. It is a dynamic parameter and changes with posture. The pelvic incidence is the angle created by a line perpendicular to the sacral platform at its midpoint and the line that connects this midpoint with the midpoint of the femoral head (Fig. 1). It is a morphological parameter and remains constant for any given person. A lesser pelvic incidence corresponds to less lumbar lordosis, and with a lesser sacral slope implies a more limited range of anterior and posterior pelvic tilt [26] (Fig. 2). In the study by Zárate-Kalfópulos et al. the reported sacral slope for Asians was 36.3 and $39.9^{\circ}$ for Caucasians. The pelvic incidence for Asians was 47.8 and $51.9^{\circ}$ for Caucasians. The ethnic difference in pelvic incidences may also point to a necessary difference in direction of thigh and femur elevation in order to achieve maximum pelvic rotation (Fig. 3). Thus when McRoberts' manoeuvre is performed in Asians, there may be less flexibility for rotation and the mechanism of movement may be different. Hence the dramatic change in angles as suggested by Gherman et al. [15] and Gonik et al. [27] in the pelvimetry models may not be achieved, leading to a failure of McRoberts' manoeuvre.

The practice of the accouchers may also affect the success of McRoberts' and suprapubic pressure. In Hong Kong, midwives conduct all spontaneous vaginal deliveries. When they encounter shoulder dystocia, they will only perform McRoberts' and suprapubic pressure whilst waiting for the obstetricians to arrive. Hence midwives may use more time and effort in performing McRoberts' manoeuvre, contributing to its success. In contrast, all instrumental deliveries are conducted by obstetricians, who may adopt other manoeuvres earlier, either due to their familiarity and knowledge of the other manoeuvres, or to their reluctance for forceful traction of fetal neck during McRoberts'.

Gonik et al's mathematical model suggests that McRoberts' manoeuvre may reduce the traction force

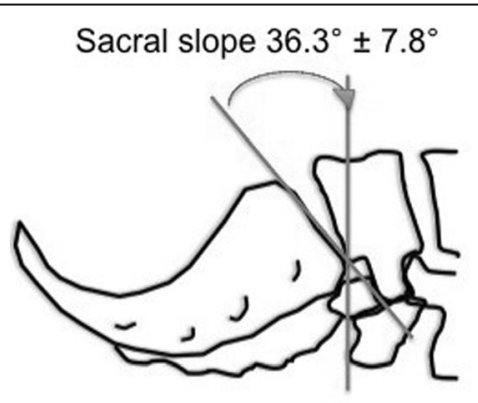

Asian

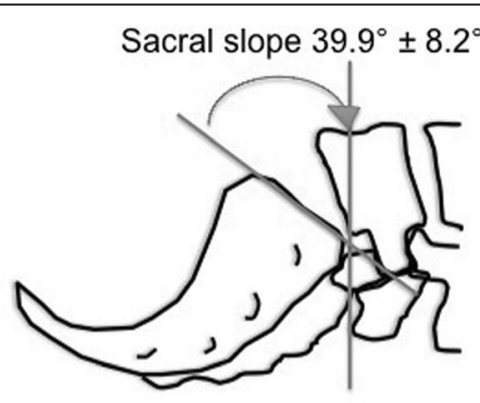

Caucasian

Fig. 2 Difference in sacral slope angles between Asian and Caucasian pelvises. - Larger sacral slope angle in theory allows greater degree of movement of Caucasian pelvises. Based on data from Zárate-Kalfópulos B, Romero-Vargas S, Otero-Cámara E, Correa VC, Reyes-Sánchez A. Differences in pelvic parameters among Mexican, Caucasian, and Asian populations. J Neurosurg Spine. 2012;16:516-519 [23] 


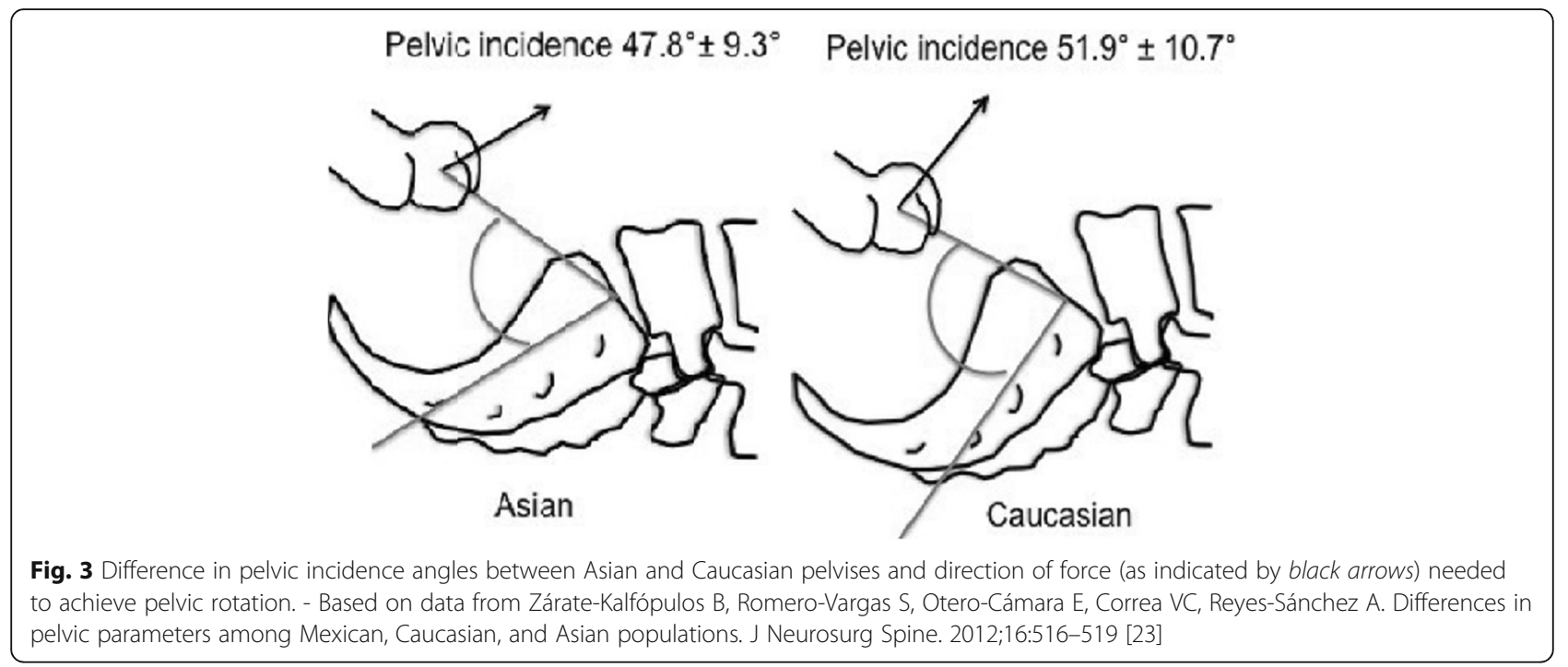

needed to achieve delivery by $50 \%$ [27]. However, it does not reduce the risk of brachial plexus injury in clinical practice, as shown by MacKenzie et al's study where the increased use of McRoberts' actually resulted in an increase in brachial plexus injury [13]. The injury may have resulted from undetected failure of McRoberts' manoeuvre in cases where there has been delayed descent of the fetal shoulders, but in an effort to achieve delivery accouchers might have applied an excessive traction during a persistent McRoberts' procedure, resulting in injury [28]. Hence, proper training is essential to ensure safe relief of shoulder dystocia [29], and accouchers should have regular high fidelity training to achieve competence in conducting all manoeuvres [30]. McRoberts' manoeuvre should still be performed firstly, as it is simple to learn and perform, and if it succeeds can eliminate the need for internal manoeuvres, which may increase the risk of fetal injury under inexperienced hands [3].

Our finding of the association between instrumental delivery and failure of McRoberts' manoeuvre and suprapubic pressure may be controversial in clinical practice. As the failure rate after instrumental delivery is high, it is debatable whether the operator should recourse immediately to rotational methods, which is associated with a higher success rate and low morbidity [3]. By shortening the head-to-shoulder delivery interval, the chance of hypoxic ischemic injury may be reduced [2]. However, if the mechanism of the failure is the delayed decent of the posterior shoulder, it is debatable whether more time should be allowed for the shoulder to descend spontaneously before starting aggressive intervention.

Our study is limited by an ethnically Asian cohort without Caucasians for direct comparison. Whether our findings are applicable to other ethnic groups need further investigation, as their pelvic configuration may be different [31]. However, our study is strengthened by a sizable cohort, comprehensive recruitment and uniform management of shoulder dystocia through the years due to routine drills and monthly audit reviews. We did not further separate the success rates for McRoberts' manoeuvre from suprapubic pressure as both were commonly performed simultaneously, making the estimation of individual's success rate imprecise.

\section{Conclusion}

When shoulder dystocia occurs after instrumental vaginal delivery, the chance of failure of McRoberts' manoeuvre is $85 \%$, which is a significant 4.88 times higher as compared to spontaneous vaginal delivery. There should be a quick resort to other manoeuvres to expedite delivery and all operators performing instrumental delivery should be proficient in all manoeuvres. Further studies are required to substantiate the generalisability of our findings, and assess the degree of impact instrumental delivery and ethnicity has on the management of shoulder dystocia.

\section{Abbreviations}

BMI: Body mass index; Cl: Confidence interval; M+/-S: McRoberts' manoeuvre with or without suprapubic pressure; OR: Odds ratio; vs.: Versus

\section{Acknowledgements}

Not applicable.

\section{Funding}

None.

\section{Availability of data and materials}

The datasets generated during the current study are not publicly available due to the Institutional ethics committee does not permit to share the data publicly. Requests for the datasets can be directed to the corresponding author. 


\section{Authors' contributions}

ZLL, KYC and TYL conceived and designed the study, analysed and interpreted the data, wrote the manuscript. All authors have approved the manuscript.

\section{Competing interests}

The authors declare that they have no competing interests.

\section{Consent for publication}

Not applicable.

\section{Ethics approval and consent to participate}

Ethical approval for this study was obtained from the Institutional Review Board 'Joint The Chinese University of Hong Kong - New Territories East Cluster Clinical Research Ethics Committee' (Ref. No. CRE-2010.029) on 04 February 2010. The informed consent was waived by the clinical research ethics committee for the retrospective analyses.

Received: 26 February 2016 Accepted: 22 October 2016

\section{Published online: 29 October 2016}

\section{References}

1. RCOG. Green-top Guideline: Shoulder dystocia. Royal College of Obstetricians and Gynaecologists; 2012. Available from: https://www.rcog. org.uk/globalassets/documents/guidelines/gtg42_25112013.pdf. Accessed 26 Oct 2016.

2. Leung TY, Stuart O, Sahota DS, Suen SS, Lau TK, Lao TT. Head-to-body delivery interval and risk of fetal acidosis and hypoxic ischaemic encephalopathy in shoulder dystocia: a retrospective review. BJOG. 2011; 118:474-9.

3. Leung TY, Stuart O, Suen SS, Sahota DS, Lau TK, Lao TT. Comparison of perinatal outcomes of shoulder dystocia alleviated by different type and sequence of manoeuvres: a retrospective review. BJOG. 2011;118:985-90.

4. Leung TY, Chung TK. Severe chronic morbidity following childbirth. Best Pract Res Clin Obstet Gynaecol. 2009;23:401-23.

5. McFarland MB, Langer O, Piper JM, Berkus MD. Perinatal outcome and the type and number of maneuvers in shoulder dystocia. Int J Gynaecol Obstet. 1996:55:219-24

6. Hankins GD, Clark SM, Munn MB. Cesarean section on request at 39 weeks: impact on shoulder dystocia, fetal trauma, neonatal encephalopathy, and intrauterine fetal demise. Semin Perinatol. 2006;30:276-87.

7. Cheng YK, Lao TT, Sahota DS, Leung VK, Leung TY. Use of birth weight threshold for macrosomia to identify fetuses at risk of shoulder dystocia among Chinese populations. Int J Gynaecol Obstet. 2013;120:249-53.

8. Crofts JF, Bartlett C, Ellis D, Hunt LP, Fox R, Draycott TJ. Training for shoulder dystocia: a trial of simulation using low-fidelity and high-fidelity mannequins. Obstet Gynecol. 2006;108:1477-85.

9. Deering S, Poggi S, Macedonia C, Gherman R, Satin AJ. Improving resident competency in the management of shoulder dystocia with simulation training. Obstet Gynecol. 2004;103:1224-8.

10. ACOG Committee on Practice Bulletins-Gynecology, The American College of Obstetrician and Gynecologists. ACOG practice bulletin clinical management guidelines for obstetrician-gynecologists. Number 40, November 2002. Obstet Gynecol. 2002;100(5 Pt 1):1045-50.

11. Baxley EG, Gobbo RW. Shoulder dystocia. Am Fam Physician. 2004;69:1707-14.

12. Stitely ML, Gherman RB. Shoulder dystocia: Management and documentation. Semin Perinatol. 2014:38:194-200.

13. MacKenzie IZ, Shah M, Lean K, Dutton S, Newdick H, Tucker DE. Management of shoulder dystocia: trends in incidence and maternal and neonatal morbidity. Obstet Gynecol. 2007;110:1059-68.

14. Hoffman MK, Bailit JL, Branch DW, Burkman RT, Van Veldhusien P, Lu L, et al. A comparison of obstetric maneuvers for the acute management of shoulder dystocia. Obstet Gynecol. 2011;117:1272-8.

15. Gherman RB, Goodwin TM, Souter I, Neumana K, Ouzounian JG, Paul RH The McRoberts' maneuver for the alleviation of shoulder dystocia: How successful is it? Am J Obstet Gynecol. 1997;176:656-61.

16. Kallianidis AF, Smit M, Van Roosmalen J. Shoulder dystocia in primary midwifery care in the Netherlands. Acta Obstet Gynecol Scand. 2016;95: 203-9.
17. Spong CY, Beall M, Rodrigues D, Ross MG. An objective definition of shoulder dystocia: prolonged head-to-body delivery intervals and/or the use of ancillary obstetric maneuvers. Obstet Gynecol. 1995;86:433-6.

18. WHO Expert Consultation. Appropriate body-mass index for Asian populations and its implications for policy and intervention strategies. Lancet. 2004;363:157-63.

19. Gherman RB, Chauhan S, Ouzounian JG, Lerner H, Gonik B, Goodwin TM. Shoulder dystocia: the unpreventable obstetric emergency with empiric management guidelines. Am J Obstet Gynecol. 2006;195:657-72.

20. Leung TY, Leung TN, Sahota DS, Chan OK, Chan LW, Fung TY, et al. Trends in maternal obesity and associated risks of adverse pregnancy outcomes in a population of Chinese women. BJOG. 2008;115:1529-37.

21. Revicky V, Mukhopadhyay S, Morris EP, Nieto JJ. Can we predict shoulder dystocia? Arch Gynecol Obstet. 2012;285:291-5.

22. Cheung $\mathrm{TH}$, Leung A, Chang A. Macrosomic babies. Aust N Z J Obstet Gynaecol. 1990;30:319-22.

23. Zárate-Kalfópulos B, Romero-Vargas S, Otero-Cámara E, Correa VC, ReyesSánchez A. Differences in pelvic parameters among Mexican, Caucasian, and Asian populations. J Neurosurg Spine. 2012;16:516-9.

24. Pettersson K, Ajne J, Yousaf K, Sturm D, Westgren M, Ajne G. Traction force during vacuum extraction: a prospective observational study. BJOG. 2015; 122:1809-16.

25. Poggi SH, Allen RH, Patel CR, Ghidini A, Pezzullo JC, Spong CY. Randomized trial of McRoberts versus lithotomy positioning to decrease the force that is applied to the fetus during delivery. Am J Obstet Gynecol. 2004;191:874-8.

26. Lazennec JY, Brusson A, Rousseau MA. Hip-spine relations and sagittal balance clinical consequences. Eur Spine J. 2011;20 Suppl 5:686-98.

27. Gonik B, Zhang N, Grimm MJ. Defining forces that are associated with shoulder dystocia: the use of a mathematic dynamic computer model. Am J Obstet Gynecol. 2003;188:1068-72.

28. Crofts JF, Fox R, Ellis D, Winter C, Hinshaw K, Draycott TJ. Observations from 450 shoulder dystocia simulations: lessons for skills training. Obstet Gynecol. 2008;112:906-12.

29. Crofts JF, Lenguerrand E, Bentham GL, Tawfik S, Claireaux HA, Odd D, et al. Prevention of brachial plexus injury-12 years of shoulder dystocia training: an interrupted time-series study. BJOG. 2016;123(1):111-8.

30. Goffman D, Heo H, Pardanani S, Merkatz IR, Bernstein PS. Improving shoulder dystocia management among resident and attending physicians using simulations. Am J Obstet Gynecol. 2008;199:294. e1-5.

31. Yi SS, Kwon SC, Wyatt L, Islam N, Trinh-Shevrin C. Weighing in on the hidden Asian American obesity epidemic. Prev Med. 2015;73:6-9.

\section{Submit your next manuscript to BioMed Central and we will help you at every step:}

- We accept pre-submission inquiries

- Our selector tool helps you to find the most relevant journal

- We provide round the clock customer support

- Convenient online submission

- Thorough peer review

- Inclusion in PubMed and all major indexing services

- Maximum visibility for your research

Submit your manuscript at www.biomedcentral.com/submit 